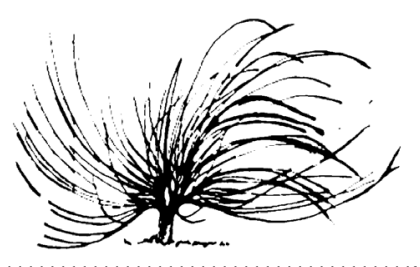

\title{
Redescubriendo la pedagogía de la esperanza de Paulo Freire
}

\author{
Enrique Vilchez Quesadal \\ Escuela de Informática \\ Universidad Nacional \\ Costa Rica \\ enrique.vilchez.quesada@una.ac.cr
}

\begin{abstract}
Resumen
Este escrito redescubre una importante obra del pensador latinoamericano Paulo Freire, llamada La pedagogía de la esperanza: un reencuentro con la pedagogía del oprimido (Freire, 2005) que publicó en el año de 1992. Después de haber sido objeto de una intensa persecución ideológica y política en su país de origen Brasil y en el exilio, Paulo Freire, con una madurez íntegra otorgada por los años y la experiencia, redefine en la Pedagogía de la esperanza, los principios de su Pedagogía del oprimido, siendo un testigo fiel de la praxis orientada a la emancipación del oprimido y del opresor. El presente ensayo relata, en un marco contemporáneo, las principales reflexiones evocadas por Freire; con la esperanza de rehabilitar en el acto educativo y su rol esencial de motor de cambio, el desocultamiento de la verdad y recurso indispensable hacia la búsqueda de la justicia social.
\end{abstract}

Recibido: 9 de marzo de 2020. Aprobado: 2 de setiembre de 2020.

http://dx.doi.org/10.15359/rep.16-1.5

1 Docente e investigador Catedrático de la Escuela de Informática de la Universidad Nacional de Costa Rica. Cuenta con una licenciatura en Educación matemática, una maestría en Tecnología e informática educativa ambos títulos emitidos por la Universidad Nacional de Costa Rica y una maestría en entornos virtuales de aprendizaje por la Universidad Técnica Nacional de Costa Rica. Es autor de más de cuarenta artículos científicos y de divulgación en las áreas de matemática e informática educativa y libros relacionados con el uso de software con fines didácticos. http://orcid.org/0000-0002-2571-5729 
Palabras clave: aprendizaje, educación, enseñanza, esperanza, pedagogía

\begin{abstract}
This essay rediscovers an important work of the Latin American thinker Paulo Freire called Pedagogy of Hope: Reliving Pedagogy of the Oppressed that he published in 1992. After having been subject to intense ideological and political persecution in his country of origin Brazil and in exile, Paulo Freire, with a full maturity granted by years and experience, redefines in the Pedagogy of Hope, the principles of his Pedagogy of the Oppressed, being a faithful witness of the praxis aimed at the emancipation of the oppressed and of the oppressor. This essay recounts, in a contemporary framework, the main reflections evoked by Freire with the hope of rehabilitating in the educational act, and its essential role as an engine of change, a disregard of the truth, which is an indispensable resource towards the search for social justice.
\end{abstract}

Keywords: education, hope, learning, pedagogy, teaching

\title{
1. Introducción
}

T a pedagogía de la esperanza: un reencuentro con la pedagogía del oprimido (2005) conmemora una fuerte reflexión retrospectiva sobre el impacto filosófico, ideológico, social, cultural y educativo que circunscribió la teoría del oprimido como un movimiento político, impulsado por el educador y pedagogo Paulo Freire desde los años sesenta hasta los noventa, del siglo pasado; aunque como veremos más adelante, tan latente en las innumerables injusticias humanas contemporáneas.

Siendo la pedagogía la ciencia que estudia las técnicas y metodologías vinculadas con la enseñanza desde un campo disciplinar (Heeren, 2019), y, la esperanza, una fe suscita evocadora de un futuro mejor, de una sociedad más justa, de una economía mundial equilibrada y en suma, del rescate del humanismo como una reacción posmodernista que intenta reivindicar los errores trágicos heredados por el capitalismo, la pedagogía de la esperanza se presenta a sí misma como un llamado 
apocalíptico de cambio, donde cada persona, en el marco de su contexto sociocultural defina bien sus luchas, comprometidas con una visión de desarrollo integradora, que favorezca la liberación del oprimido y asimismo, la liberación del opresor.

Paulo Freire reconstituye las bases en este ensayo, como género literario (Aullón, 2016), de su pedagogía del oprimido con una perspectiva renovada y, más que asumir una conceptualización teórica como ya lo había hecho en los años setenta, en un libro con ese mismo nombre, entreteje en la pedagogía de la esperanza, la esperanza misma, reflejada en la práctica de la emancipación, de la cual él fue testigo en muchos países de Europa, Latinoamérica, el Caribe, Australia y África. Sus relatos, cargados de la mística de un verdadero educador, entrañan recuerdos donde la historia se consolida como protagonista de severos cambios sociales e ideológicos, algunas veces pautados por las fuerzas dominantes y otras, por las fuerzas recesivas de trabajadores obreros, campesinos y religiosos, quienes en un despertar ante sus opresores se convirtieron en mártires y estandartes de la lucha por la libertad.

En Freire, el sueño y la utopía como revelaciones de una práctica educativa progresista reflejan el importante rol que juega la educación como un medio movilizador de índole político, al desocultar la verdad ante las víctimas de un sistema social represor. Sus fundamentos ideológicos inscritos en una época distinta y, en un tiempo y un espacio con características muy particulares, siguen aún vigentes y casi universales hacia la búsqueda de una pedagogía social que regenere la esperanza.

\section{Síntesis de las ideas del autor}

\subsection{Algunas generalidades}

Paulo Freire nació el 19 de setiembre de 1921 en Recife, Brasil, geográficamente inmerso en un ambiente de pobreza. Estudió la carrera de Derecho en la Universidad de Pernambuco, preparándose también en los campos de la filosofía y, el lenguaje de manera paralela. Desde muy joven, tras experimentar el hambre y las carencias económicas por la muerte prematura de su padre, se sintió ligado a la lucha por los más vulnerables y necesitados; tanto así, que abandonó sus incipientes inicios en la abogacía, al comprobar cómo la aplicación de las leyes, 
en muchas ocasiones, no era consistente con los valores morales y éticos que daban coherencia a su forma de pensamiento. Creció en un ambiente familiar muy religioso pluralizado en espiritista y católico (Sanz, 1998).

En 1947, Paulo fue invitado a incorporarse a la División de Educación y Cultura del Servicio Social de la Industria, conocido como SESI, en el Departamento Regional de Pernambuco. Este puesto le concedió la posibilidad de comenzar a tener un acercamiento real con lo que sería para él, la educación como práctica de la libertad. Sus primeras preocupaciones en el ámbito educativo dentro del SESI sentaron las bases por descubrir, cuáles eran las relaciones entre las escuelas de Pernambuco y otras regiones de Brasil con las familias. Desde esa época, comenzó a emerger en su ideología la firme certeza de reconocer la educación como un recurso idóneo para la democratización del currículo escolar, al abrir canales de participación en un ejercicio dialógico, entre las madres y padres de familia. Se interesó por indagar las relaciones entre autoridad y libertad manifestadas por el castigo interpuesto por los padres a sus hijos. A raíz de ello, Freire redactó un texto sobre disciplina escolar, iniciando en sus prácticas de enseñanza populares una pedagogía que lo acompañaría hasta el final de sus días: el seminario, cual recurso esencial para garantizar la capacitación y formación tanto académica como informal.

En sus inicios hacia la construcción de una pedagogía del oprimido, encontró severas diferencias de lenguaje, de naturaleza sintáctica y semántica, entre el mundo académico, al cual él pertenecía y el de las personas humildes, a quien era imperioso formar, tanto a padres como hijos. En este punto, comenzó en su visión de la educación una transformación revolucionaria de una tradición sistémica en la cual, la lectura de mundo de los educandos era completamente ignorada. $\mathrm{Y}$ de forma contemporánea, deberíamos cuestionarnos si aún en los sistemas educativos actuales de muchos de los países en el nivel de Latinoamérica, hemos superado esta concepción mecanicista de la educación. Me atrevería a aventurarme a decir que no; así lo apuntan distintos autores como Barrientos (2018) y Mujica (2019). En las universidades del siglo XXI lamentablemente se aprecia el ejercicio de prácticas educativas de naturaleza vertical, con muy pocos esfuerzos de aproximación entre los nuevos contenidos o cosmovisiones del docente y los conocimientos previos del alumnado. El discurso del profesor es interpretado como 
el único saber posible, como una sabiduría omnipresente capaz de flagelar cualquier otro conocimiento subyacente. Esto para Paulo Freire, en años posteriores, se convertiría en una dura crítica de la educación vacía, que no respeta lo que él denominó el saber de experiencia de hecho; además de recoger la importancia política de la educación, al tener, en este marco, la responsabilidad de evitar la reproducción de cualquier tipo de autoritarismo intelectual o social.

El contacto de Freire con los hijos de trabajadores rurales y urbanos, durante todo el desarrollo de su pensamiento educativo, lo hizo sensibilizarse ante el implícito miedo a la libertad mostrado por la clase trabajadora con respecto a su opresor: el jefe, el patrón, la clase dominante. La conducta de injusticia de los opresores era justificada por los propios oprimidos, bajo una ideología que les tenía prohibido cuestionar el régimen que les proporcionaba un trabajo y, con ello, un medio de subsistencia.

\subsection{Papel de la educación como motor de cambio social y político}

Paulo siempre demandó la necesaria democratización de la escuela, utilizando como medio principal la formación permanente de todos sus participantes: profesores, estudiantes, personal administrativo, personal de mantenimiento y la familia. La formación daría a cada uno la posibilidad de comprender el contexto y de racionalizar, en un proceso dialéctico reflexivo, una visión de futuro compartida que desembocaría en definir con claridad los objetivos cognitivos, culturales, políticos y sociales de la institución. Cada uno debía asumir una postura concientizada de la importancia de su trabajo hacia el logro de estos fines. Aquí cabe mencionar, la actual disparidad existente en los sistemas educativos formales, donde el currículo es entregado de forma acabada a los docentes, a los alumnos y a las comunidades. Los principios de Freire, ya señalados, se mantienen hoy por hoy en el olvido para las políticas educativas formuladas en el ámbito de los escritorios, en oficinas gubernamentales donde priva aún el poder de las clases elitistas, quienes definen qué tipos de conocimientos y bajo qué metodologías deben ser aprendidos por la población en general. Feldfeber y Andrade (2016), señalan que en los últimos años estas posturas neoliberales han ido cambiando, pero que, en la actualidad, la hegemonía política de los 
estados aún prevalece en las realidades educativas de América Latina. La cúpula de este perverso sistema, de forma muy conveniente, culpa, ocasionalmente, a las dormidas bases de la estructura educativa, quienes a su vez sienten la incapacidad de comprender su importante rol protagónico para incentivar un cambio. En este sentido, las autoridades de gobierno se convierten en represoras del mantenimiento de intereses políticos particulares, que reproducen una educación bancaria basada en el repositorio de información, más que en el desarrollo de un pensamiento crítico. Los oprimidos, los docentes que día a día luchan contra las adversidades de una realidad educativa enmascarada en discursos que validan su complicidad; sin darse cuenta, asumen la ideología del progreso modernista que acaba con la esperanza de una pedagogía que se libere de este autoritarismo organizacional. En él, solo es lícita la participación de especialistas en materia curricular, renunciándose a buscar una democratización en la elección y la enseñanza de los contenidos.

Ese proceso de liberación, como bien lo apunta Freire (2005), es doloroso, lento y profundo, necesario, muchas veces, pero no suficiente para mover la hegemonía de la opresión. Pese a ello, sin él no es posible la movilización de los sujetos a la acción, que da paso a la transformación de la realidad imperante.

\subsection{El exilio de Paulo Freire: un camino retrospectivo de la pedagogía del oprimido}

Paulo Freire fue exiliado de su país nativo, Brasil, en el año de 1964, ante un golpe de Estado, llamado por sus precursores la revolución, que lo perseguiría política e ideológicamente hasta principios de los años ochenta, tiempo en el cual, tuvo ocasión de regresar de esta trama, como él la llama, cargada de historia, cultura y pluralizada, a raíz de su contacto con diversos contextos o realidades prestadas donde asumió una pedagogía de la esperanza bajo una visión crítica, que le permitiría, años más tarde, publicar la primera edición de la Pedagogía del oprimido, en Nueva York, Estados Unidos, ya para el año de 1970.

En 1964, Paulo arribó a La Paz, en Bolivia, donde a razón de otro golpe de Estado su estancia fue muy corta, abriéndose paso hacia tierras chilenas que lo abrazarían como asesor del famoso economista Jacques Chonchol, presidente del Instituto de Desarrollo Agropecuario: INDAP. Este puesto puso en contacto a Freire con los campesinos que 
proclamaban su derecho a tener tierras y la libertad para producir en ellas, con la intención de generar el capital indispensable concurrente hacia una vida digna. Se encontró en un escenario donde los oprimidos eran más conscientes del perjuicio que les ocasionaban sus opresores, extrapolando sus necesidades a un ámbito cultural y también cognitivo. $\mathrm{Su}$ labor, a través de cursos de formación con educadores encaminados a conciliar una reforma agraria, le permitió ser testigo una vez más, de la radicalidad eclosionada por posiciones políticamente sectarias, rígidas y dogmáticas que desembocarían para el año de 1969 en serios disturbios sociales en Chile.

Mientras todo esto ocurría, su pedagogía del oprimido cobraba vida en la palabra escrita entre los años de 1967 y 1968, como una respuesta sociocrítica hacia la domesticación operante por parte de las clases dominantes ante las más desfavorecidas, necesitadas de una pedagogía capaz de encausarlos a una comprensión de su propia opresión, muchas veces justificada por el miedo. El sueño y la esperanza en la pedagogía del oprimido constituyen el motor que moviliza el cambio, no garantiza ese cambio, solamente lo hace visible en el horizonte, un horizonte nunca pensado, nunca vivido en la imaginación y en las conjeturas hacia un futuro más justo y equitativo. Paulo Freire concedió un lugar preponderante al desarrollo de una educación popular, es decir, una enfocada en organizar a las comunidades hacia una movilización de cambio, que venciera las ideologías y poderes de la clase dominante a través de una lucha que marcara sus límites de tolerancia.

En 1969, Paulo junto a su familia, retoma el exilio como profesor invitado en la prestigiosa Universidad de Harvard. En el año de 1970, pese a todos sus retractores y perseguidores políticos logra publicar la obra Pedagogía del oprimido en idioma inglés, que posteriormente sería traducida a otros como: el francés, el italiano, el español y el portugués.

En el año 1971, fundó en Suiza el Instituto para la Acción Cultural auspiciado por el Concilio Mundial de Iglesias, donde, a su vez, fue profesor en la Facultad de Ciencias de la Educación de la Universidad de Ginebra. Más adelante continuó el desarrollo de su pensamiento trabajando con la UNESCO y como profesor invitado en múltiples universidades alrededor del mundo, donde se encargó de divulgar y defender sus propuestas para atender la alfabetización de las clases populares. Hasta el año de 1979 logra regresar a Brasil, específicamente a 
Sao Paulo, donde ocupó distintos puestos académicos en universidades y donde falleció el 2 de mayo de 1997 (Ocampo, 2008).

\subsection{Aportes de la pedagogía de la esperanza hacia la bús- queda de una educación progresista}

La pedagogía de la esperanza (2005) señala la importancia de la evolución del acto educativo que le transfiere una connotación progresista. Paulo Freire conceptualiza en este ensayo el progresismo educativo como un acto rehabilitador, donde el momento particular del educando, en cuanto a sus posibilidades cognitivas y de comprensión de la realidad, sean el punto de partida, evitando así, desconocer los saberes que forman parte inherente de los aprendices cuando llegan a las instituciones de enseñanza.

La educación mecánica y reproductiva debe ser reemplazada por un acto que le otorgue al alumnado la oportunidad de analizar su entorno, su realidad y las posibilidades de su transformación. El estudiante tiene el deber de asumir con seriedad un rol crítico que la haga trascender de sus conocimientos iniciales a los objetivos de una enseñanza más plena, tales como: aprender a hacer, vincular la práctica con la teoría, crear relaciones conceptuales y analíticas, resolver problemas, entre otras. En la actualidad, a mi juicio, este es un valor que se ha confundido en la inmediatez de un mundo plagado de mecanismos de comunicación masiva y ecosistemas de aprendizaje, donde se distorsiona el trabajo duro con un quehacer insustancial basado en el entrenamiento hueco.

La enseñanza, como bien lo propone Freire, debe estar regulada por reglas claras y firmes. Aprender y aprehender son procesos exigentes que demandan educadores creativos, orientadores, estimuladores y disciplinados. Con el ejemplo y la coherencia profesional del maestro, los estudiantes, de la misma manera, irán incorporando esa rigurosidad a sus prácticas de aprendizaje en un proceso que debería iniciar en edades muy tempranas en la escuela, como también, el ejercicio de aprender a aprender, aprender a hacer y a racionalizar los hechos humanos y científicos de forma crítica. Pero, si se piensa en la formación de los formadores, ¿están las universidades en el nivel de Latinoamérica, realmente asumiendo el reto de germinar y evolucionar ese tipo de pensamiento divergente?, una renuncia a ello provocaría, como bien lo dice el dicho popular: "pedir peras al olmo". La educación superior 
tiene, de manera subyacente, el importante reto de propiciar el desarrollo de un pensamiento crítico, pese a la masificación que en muchos escenarios devela intereses de naturaleza mercantilistas. El paradigma positivista, en las instituciones universitarias, propone la urgencia de renovados enfoques, donde se evidencie en la formación de los educandos la integración del conocimiento, su comprensión, sus relaciones con el entorno y sus consideraciones éticas con miras a promover una transformación de la sociedad (Matías y Fernández, 2018).

También, la educación progresista se relaciona en Paulo Freire con el desafío. La práctica educativa no debe fundamentarse solo en el planteamiento de conocimientos abstractos e intangibles. Tal acepción ocultaría las dimensiones históricas, culturales y políticas que acompañan cualquier suceso creativo. Irremediablemente educar exaltando la capacidad de análisis, indagación, formulación, síntesis, conjetura y resolución de problemas, demanda un acompañamiento docente no autoritario, pero sí directivo, ético, transparente, humilde y tolerante, donde los nuevos conocimientos emerjan no por la transmisión virulenta sino por la significación de sentido. Ha de notarse aquí en el pensamiento de Freire, una influencia del aprendizaje significativo propuesto por Ausubel.

La educación progresista en la Pedagogía de la esperanza, publicada en el año de 1992, relata un sueño educativo adelantado a su tiempo histórico, que de manera vivaz vendría, en los años subsiguientes, a alimentar las teorías y enfoques modernos de la educación, al compartir muchas de sus aristas. El aprendizaje por proyectos, el basado en problemas (ABP), el colaborativo, el aprendizaje basado en casos, el inverso, por solo mencionar algunos enfoques, buscan incentivar la incubación de relaciones interdisciplinares teórico-prácticas, donde el alumnado rescate la aplicabilidad de los conocimientos en la puesta en marcha de procesos de investigación, de resolución de problemas y de una construcción social de lo que se aprende (Orozco y Perochena, 2016). Todas estas tendencias educativas contemporáneas rescatan, en alguna medida, las ideas de Paulo Freire, quien, en su lucha por la clase trabajadora, se enfocó en desarrollar una pedagogía para la educación popular (Ocampo, 2008). 


\subsection{Aportes de la pedagogía de la esperanza en los procesos de enseñanza y aprendizaje}

Freire, en su pedagogía de la esperanza, reconoce como esencial el manejo profundo del conocimiento para una enseñanza efectiva. Un buen docente debe rehacer su cognoscitividad, al procurar compartir sus saberes con los estudiantes de manera innovadora, disruptiva y no mecánica. Bajo esta perspectiva, enseñar es una labor para la cual es necesario prepararse académica y profesionalmente, por lo tanto, no cualquiera está en capacidad de poderrealizarla. En este sentido, es interesante observar en nuestras sociedades, cómo la labor académica y humana de los educadores es vista en muchos contextos con desdén y menosprecio. La figura del maestro se suele vincular con salarios mal remunerados, sindicatos que garantizan únicamente derechos absurdos y abusivos, posturas en la cultura popular que asocian el fracaso de una persona por solo el hecho de dedicarse a la docencia y, en general, una visión no científica de la tarea educativa.

La pedagogía de la esperanza (2005) nos invita a tomar una conciencia más plena sobre la necesaria formación y capacitación del profesorado bajo una vertiente científica y experiencial, donde el empleo consistente de los materiales disponibles, los métodos y las técnicas educativas sean la clave. La experiencia para Freire es un aspecto medular en la condición de un buen docente, que puede librar a la enseñanza de la dicotomía entre los conocimientos expertos y los saberes populares. Estos últimos tan importantes como los primeros, por el respeto que merece la percepción particular de mundo proveniente de los educandos.

El diálogo en los procesos de enseñanza y aprendizaje define la operatividad de una pedagogía basada en la esperanza, donde el hilo conductor de la trama educativa lo constituya el debate abierto, siendo este el punto de partida para colisionar las ideas nuevas con los aprendizajes ya adquiridos. Arrastrar al alumnado a una comprehensión crítica de su propia realidad y de la sociedad circundante, transforma sus sistemas de codificación y decodificación, en muchos casos dormidos, por las situaciones de opresión y condiciones deshumanizadas en las que pueden encontrarse. Para Freire, esta fue una constante vitalicia en sus múltiples visitas a muchos países a lo largo de toda América Latina y otras partes del mundo, siendo testigo y cómplice en el exilio, de modelos de enseñanza y aprendizaje positivistas, como 
los que aún imperan en muchas universidades, donde en el currículo oculto hay una amplia aceptación de ver a los alumnos como un repositorio de información. Patiño (2020), hace referencia al término currículum oculto y lo define así:

Es el currículo paralelo, currículo vivido, currículo real; asumiendo que el currículo oculto son todos los elementos que, sin estar contemplados en el currículum formal de la institución, se inculca a través de la práctica docente cotidiana en la educación superior, que incluso, puede llegar a tener mayor significación que los aprendizajes explícitos en el currículo oficial. (p. 64)

Es justo decir, que muchas veces la relación de diálogo en la enseñanza y el aprendizaje en el nivel superior se rompe, pues el científico, el investigador, el experto de contenido en la universidad visualiza en sus clases verticales el único medio que valida el paso auténtico de la erudición pura, creada y construida para ser transmitida a las nuevas generaciones.

En cuanto a la tecnología y los procesos educativos, aunque conoció una tecnología muy distinta a la actual, por su muerte en abril de 1997, su posición siempre fue muy cauta. Advirtió en esta pedagogía de la esperanza (2005), los peligros de posturas radicales, hoy en día, ya consumadas en hechos. Al "endiosar" (tecnofilia) o "endemoniar" (tecnofobia) la tecnología, se pierde su verdadero sentido: ponerla al servicio del bienestar de las personas y de manera más particular, del entendimiento y criticidad de los estudiantes.

\section{Conclusiones}

En la Pedagogía de la esperanza (2005), Paulo Freire, crítico y decidido, vuelve a reflexionar y analizar los principios que en los años sesenta y setenta fundaron los cimientos de la pedagogía del oprimido. Con un tono, en este texto, más maduro, después de haber presenciado la praxis de sus ideologías y metas en el ámbito educativo como un redescubrimiento histórico, cultural y político, redefine, de una forma revolucionaria, los preceptos de una educación progresista, tan progresista que, pese a haber sido publicada esta obra en el año de 1994, sigue tan vigente como sus otras posiciones liberadoras. 
Con una misión casi apostólica, expone, en este ensayo, la necesidad de continuar la senda por una democracia que guíe al desafío, al descubrimiento y al desocultamiento de la verdad. Allí los educadores, los alumnos, la familia y la comunidad en general tienen un deber insólito con la sociedad, al luchar contra la pobreza de cuerpo y alma, el racismo, la deshumanización y la falta de tolerancia hacia la multiculturalidad o la simple diferencia de opiniones.

La educación hacia el pensamiento reflexivo es una clara ambigüedad en muchas instituciones de enseñanza en Latinoamérica, sobre todo en las universidades, las cuales se muestran difuminadas en sus quehaceres docentes, de extensión y de investigación. Hay una ruptura evidente del papel social de las universidades con sus marcos de acción, fragmentados por antagonismos que, lejos de producir una unidad de diálogo con los sectores humanos más vulnerables, auspician el crecimiento de la brecha causada por las injusticias y las desigualdades.

El culto a la razón, al punto de su idolatría con fines utilitarios, ha eclosionado lo que algunos denominan la posmodernidad. Según Hernández (2016), la posmodernidad presenta tres ejes esenciales en su pensamiento: la negación de la razón, la supresión de la metafísica y la incapacidad para la transformación. De allí que, está más interesada en los valores y los sentimientos, concibe lo religioso como un acto del individuo y no de la sociedad y, se enmarca en un profundo mimetismo circunstancial que acepta su entorno. Ella, en la mejor de sus visiones, procura reivindicar el espíritu humanista en las concepciones de lo que se debería entender como modernidad y avance sociocultural. Paulo Freire no niega la importancia del uso del raciocinio que procura erradicar las verdades absolutas, sino la aniquilación de los virus propagados por una comprensión del mundo donde unos pocos acumulan la riqueza. Tampoco niega la plenitud axiológica, ética ciudadana y moral que es necesario volver a cultivar en una cosmovisión colectiva. $\mathrm{Y}$ al respecto de la modernidad, el mismo Freire (2006) señala:

Yo espero, convencido de que llegará el momento en que, pasada la estupefacción ante la caída del muro de Berlín, el mundo se recompondrá y rechazará la dictadura del mercado, fundada en la perversidad de su ética de lucro. [...] Prefiero ser criticado de idealista y soñador inveterado por continuar, sin vacilar, apostando al ser humano, batiéndome por una legislación que lo defienda 
contra las embestidas agresivas e injustas de quien transgrede la propia ética. La libertad del comercio no puede estar por encima de la libertad del ser humano. (p. 128)

En nuestras sociedades contemporáneas, las posturas tecnocentristas al servicio de intereses empresariales e industriales han ocasionado serios problemas en el ámbito mundial, como: el calentamiento global, la pobreza extrema, la erosión de los suelos, la contaminación ambiental y la inseguridad del orbe, por solo mencionar algunos de ellos.

La posmodernidad reclama a gritos la urgencia de un nuevo camino. Uno que dignifique la pedagogía de la esperanza a través de una nueva lectura del mundo, donde se consagre la virtud revolucionaria hacia la búsqueda de la libertad, la felicidad y el bienestar social.

\section{Referencias}

Aullón, P. (2016). Ideas de la literatura y teoría de los géneros literarios. España: Ediciones Universidad de Salamanca.

Barrientos, P. (2018). Modelo educativo y desafíos en la formación docente. Revista Horizonte de la Ciencia, 8(15), 175191. Recuperado de http://revistas.uncp.edu.pe/index.php/ horizontedelaciencia/article/view/275/289

Feldfeber, M. y Andrade, D. (2016). Políticas educativas en América Latina en el siglo XXI. Balance y perspectivas. Revista Dossier, 39, 7-10. Recuperado de http://revistascientificas.filo.uba.ar/index.php/iice/article/download/3994/3580

Freire, P. (2005). Pedagogía de la esperanza. México: Siglo Veintiuno Editores.

Freire, P. (2006). Pedagogía de la autonomía: saberes necesarios para la práctica educativa. México: Siglo Veintiuno Editores.

Heeren, M. (2019). Problematización epistémica de la pedagogía: Algunas definiciones y aproximaciones. REIDOCREA, 8, 133-141. Recuperado de https://digibug.ugr.es/handle/10481/57748

Hernández, G. (2016). Globalización y posmodernidad: Elementos imprescindibles para la reflexión política. Revista STATUS, 1(1), 61-75. Recuperado de http://revista-status.uanl.mx/index.php/ status/article/view/7/7

Matías, A. y Fernández, O. (2018). Desafíos epistemológicos de la educación superior en el siglo XXI. Revista Cadernos de 
Pesquisa, 25(1), 11-22. doi: http://dx.doi.org/10.18764/21782229.v25n1p11-22

Mujica, F. (2019). Análisis crítico del currículo escolar en Chile en función de la justicia social. Revista Educare, 24(1), 1-14. doi: http://doi.org/10.15359/ree.24-1.25

Ocampo, J. (2008). Paulo Freire y la pedagogía del oprimido. Revista Historia de la Educación Latinoamericana, 1(10), 5772. Recuperado de https://revistas.uptc.edu.co/index.php/ historia_educacion_latinamerican/article/view/1486/1482

Orozco, V. y Perochena, P. (2016). Trabajo por proyectos. Cambio metodológico para el protagonismo del estudiante en Educación Infantil (2-3 años). Revista de Estudios y Experiencias en Educación, 15(29), 151-164. Recuperado de https://dialnet.unirioja.es/ servlet/articulo?codigo $=5738273$

Patiño, A. (2020). El Currículum oculto en la educación universitaria: Un estudio de caso en la Universidad de Panamá. Revista Acción y Reflexión Educativa, 45, 60-85. Recuperado de https:// revistas.up.ac.pa/index.php/accion_reflexion_educativa/article/ view/1142/955

Sanz, F. (1998). Significado histórico de Paulo Freire. Revista Interuniversitaria de Formación del Profesorado, 1(33), 53-59. Recuperado de https://dialnet.unirioja.es/servlet/articulo?codigo=117992 